\title{
Prevalence and associated survival of high-risk HPV- related adenoid cystic carcinoma of the salivary glands
}

\author{
XU QIAN $^{1 *}$, ANDREAS M. KAUFMANN ${ }^{2 *}$, CHAO CHEN $^{1}$, GEORGIOS TZAMALIS ${ }^{1}$, \\ VEIT M. HOFMANN ${ }^{1}$, ULRICH KEILHOLZ ${ }^{3}$, MICHAEL HUMMEL ${ }^{4}$ and ANDREAS E. ALBERS ${ }^{1}$ \\ ${ }^{1}$ Department of Otorhinolaryngology, Head and Neck Surgery, Charité-Universitätsmedizin Berlin, \\ Campus Benjamin Franklin, Berlin; ${ }^{2}$ Clinic for Gynecology, Charité-Universitätsmedizin Berlin, Campus Mitte and \\ Benjamin Franklin, Berlin; ${ }^{3}$ Charité Comprehensive Cancer Center, Charité-Universitätsmedizin Berlin, Charitéplatz 1, \\ 10117 Berlin; ${ }^{4}$ Department of Pathology, Campus Benjamin Franklin, Charité, Universitätsmedizin, Berlin, Germany
}

Received February 19, 2016; Accepted March 30, 2016

DOI: 10.3892/ijo.2016.3563

\begin{abstract}
Adenoid cystic carcinoma (SACC) is a rare malignancy, but a frequent subtype in minor and major salivary glands. The molecular alterations or biomarkers that underlie its development and progression as well as therapy outcomes are poorly characterized. The main study goal was to investigate reliable biomarkers and patient-related factors that may have impact on recurrence and long-term survival of SACC. The prevalence of human papilloma virus (HPV) in SACC was determined by HPV-DNA genotyping and p16 immunostaining. Epithelial growth factor receptor (EGFR), p53 and Ki-67 expression were also evaluated. Twenty-eight (42\%) of 67 patients were HPV-DNA positive. Kaplan-Meier analysis indicated that SACC patients with metastases $(\mathrm{P}=0.03)$ had a poor overall survival (OS) and a shorter recurrence-free survival $(\mathrm{P}<0.001)$. Positive resection margins significantly predicted shorter recurrence-free survival $(\mathrm{P}=0.01)$. In the multivariate analysis, non-metastatic disease $(\mathrm{P}=0.033)$ and p16 positivity $(\mathrm{P}=0.005)$ have shown their prediction value for OS while non-metastatic disease $(\mathrm{P}=0.002)$, HPV positivity $(\mathrm{P}=0.041)$ and negative resection margin predicted a better recurrence-free survival. The present study documents for the first time the positivity for HPV infection and overexpression of certain markers (p16, Ki-67, EGFR and p53) used in diagnostics in SACC as well as characterizes clinical entities. These factors might be exploited in the future as biomarkers for
\end{abstract}

Correspondence to: Dr Andreas E. Albers, Department of Otorhinolaryngology, Head and Neck Surgery, CharitéUniversitätsmedizin Berlin, Campus Benjamin Franklin, Hindenburgdamm 30, D-12200 Berlin, Germany

E-mail: andreas.albers@charite.de

${ }^{*}$ Contributed equally

Key words: human papilloma virus, salivary gland adenoid cystic carcinoma, survival, prevalenve, p15, p53, Ki-67, epithelial growth factor receptor its prognostic value. Using the clinical and pathological basis for predicting different outcomes could significantly facilitate SACC stratification and potentially directing treatment.

\section{Introduction}

Salivary gland carcinoma (SGC) is a rare malignancy with an incidence rate of approximately 1 per million per year in the United States (1) and Europe (2). SGC may arise in all major or minor salivary glands and may have a variety of histologic and biologic characteristics that have been summarized in a recent WHO-classification schema (3). With regard to all locations, mucoepidermoid carcinomas, polymorphous low-grade adenocarcinoma and the adenoid cystic carcinoma (SACC) are the most frequently occurring histologic types $(4,5)$. Studies with patient-collectives from Western Europe found that SACC are the most frequent type $(2,6)$. Although the etiology of SGC remains unclear, prior exposure to radiation, a history of benign salivary gland tumor and a deficiency of nutrients, particularly vitamins A and C have been identified as SGC risk factors (7-9). Epidemiologic studies indicate that the increased rates of SGC after exposure to carcinogens like nickel, chrome, asbestos, cement are possible, but there is no proof yet. Increasingly genetic aberrations are identified in SGC, none of them specific for a certain histological type. DNA of a variety of viruses with oncogenic potential such as EBV, CMV and HHV-6 to 8 was isolated from SGC, but this finding could not be linked to the development of malignancy yet (10).

Today, human papillomavirus (HPV) has been widely accepted as a cause for a subgroup of squamous cell carcinoma of the head and neck area (HNSCC) $(11,12)$. Infections with these viruses are linked to the highest risk for transformation to invasive carcinoma (13). There is very rare and sometimes controversial information about HPV infections in SGC and SACC specifically (14-19) suggesting an association between HPV and certain salivary gland neoplasms. However, the clinical significance of these findings remains elusive. One intention of the present study was to systematically investigate the HPV status in SACC tumor tissues. In HPV-related HNSCC and cervical carcinoma, p16 expression correlates highly with the presence of oncogenic HPV-DNA (20). Therefore, p16 is 
considered a specific marker equivalent to DNA-sequencing for high-risk HPV (HR-HPV) and is widely used in routine histopathological screening (20). Clinically important is that the presence of high-risk HPV and p16 expression in HNSCC is correlated with a better survival as compared to tumors with no evidence of HPV infection (21-23). Both HPV-DNA and the expression of p16 were investigated in the present study cohort of SACC.

In HNSCC, HPV-positive tumors are characterized by certain clinical and pathological characteristics, the expression of certain cell cycle proteins and genetic changes that are different from HPV-negative HNSCC $(24,25)$. TP53 mutations are by far the most common and present in $\sim 70 \%$ of HPV-negative HNSCC patients, but rare in HPV-related HNSCC as p53 is targeted by E6 protein (26). The prognosis also changes with the status of epithelial growth factor receptor (EGFR) expression. In one study, HNSCC positive for p16 expression showed a better 5-year-survival (FYS) than p16-negative tumors (84 vs. 49\%). If EGFR and p16 were co-expressed the FYS increased to $93 \%$. If tumors were only positive for EGFR, but negative for p16, FYR was decreased (21). In analogy to investigate the significant differences in survival from the subgroups classified by HPV infection in the HNSCC, we also performed p53 and EGFR immunostaining in SACC specimens with the aim to evaluate the association between p53 and EGFR expression with HPV status in patients with SACC. Until now no relevant universal prognostic indicators could be derived from clinical data, histological or immunohistochemical markers. Ki-67 has been reported as a proliferation marker related to a poor survival in SGC (27).

Since the advances in treatment modalities have not achieved a significant impact on the survival of patients with SACC, the discovery of biomarkers and potential targets are of high interest. In the present study, we propose to identify HPV-subtypes in SACC and to correlate them with other characteristics of the patients with the aim to uncover potentially novel prognostic and predictive molecular signatures and therapeutic targets.

\section{Materials and methods}

Patients and tissue specimens. The present study was approved by the Institutional Review Board of CharitéUniversitätsmedizin Berlin, Germany (EA4/035/08). Sixty-seven consecutive patients with sufficient amounts of banked biological material, data on clinical follow-up and the confirmed pathologic diagnosis of SACC, and with no prior history of malignancies and treatments were included. Archival formalin-fixed, paraffin-embedded (FFPE) SACC of the head and neck area were obtained from the Department of Pathology, Charité University Medicine, Campus Benjamin Franklin, Germany and were collected from 1982 to 2007. Data on the TNM classification were retrieved from the pathology database and patient charts. Overall survival (OS) and recurrence-free survival (RFS) was calculated from the date of diagnosis.

DNA extraction and HPV genotyping. FFPE tissues were sliced at $10 \mu \mathrm{m}$ thickness and collected in a sterile, nucleic acid-free microtube. For each tube, 3 sections of a total of
$30 \mu \mathrm{m}$ thickness were carefully collected. The proceeding and the following section of each series was stained by hematoxylin and evaluated for the presence of tumor tissue. As a control for cross contamination, HPV free tissue specimens of murine origin, which were always negative for HPV and $\beta$-globin, were cut in between SACC patients specimens. After deparaffinization of FFPE tissues, the genomic DNA was extracted by QIAamp DNA FFPE Tissue kit (Qiagen, Hilden, Germany) following the manufacturer's instructions. DNA-concentrations were measured by NanoDrop (NanoDrop ${ }^{\mathrm{TM}}$ 2000/2000c spectrophotometers; Thermo Fisher Scientific GmbH, Dreieich, Germany). Then GP5 $5^{+} /$bio- $^{+}$PCR followed by Multiplexed Genotyping readout was performed exactly as described by Schmitt et al $(28,29)$. Each PCR experiment included specimens from cervical cancers, which were proved infected by high-risk HPV as positive control, and several specimens lacking template DNA as contamination control.

Following PCR amplification, $10 \mu 1$ of each reaction mixture was subjected to hybridization to Luminex beads coupled to HPV type-specific probes and analysed on a Bio-Plex 200 (Bio-Rad Laboratories, Hercules, CA, USA). The results were concluded as the mean fluorescence intensity (MFI) of at least 50 beads per set. For each sample, the assay was performed twice in independent experiments.

The following HPV types were discriminated and genotyped: high-risk HPV 16, 18, 31, 33, 35, 39, 45, 51, 52, 56, 58, $59,68,73$ and 82 ; putative HR (pHR) types 26,53 and 66 ; and low-risk (LR) types 6, 11, 40, 42, 43, 44 and $70(29,30)$.

Importantly, within this assay, it is possible to detect multiple simultaneous infections (28). A sample was regarded positive when the MFI value was 3-fold higher than the background MFI value and borderline at 2-fold. The assay detects 10-1000 HPV copies depending on the HPV type. Net MFI values above 5 MFI were defined as positive reactions. A $\beta$-globin specific PCR was included to verify sufficient DNA content.

To assess DNA-fragmentation a specific PCR was performed. Some FFPE sections dated back to 1982. Due to non-buffered formalin use until 1995 this may have led to DNA fragmentation and therefore false negative HPV-PCR. Therefore, on each sample with a negative $\beta$-globin result a PCR was performed to assess the grade of DNA-fragmentation as previously described. Finally, the presence of 100-, 200-, 300- and 400-bp bands was evaluated on a $2 \%$ agarose gel (31).

Immunohistochemistry. Immunostaining of SACC and surrounding normal specimens was done using 5- $\mu \mathrm{m}$ sections of FFPE from the same series of sections that were used for DNA extraction. The sections were processed by the avidin-biotin-peroxidase method (ABC) using the Vectastain Elite ABC kit (Vector Laboratories, Burlingame, CA, USA) and stained with a mouse anti-p16 antibody (clone DCS-50; Neomarkers, Inc., Fremont, CA, USA) or mouse anti-human EGFR monoclonal antibody (Dako, Glostrup, Denmark). A biotinylated secondary goat anti-mouse antibody was added for $20 \mathrm{~min}$ at room temperature after a washing step. Then the color reaction was developed using the APAAP-Red-kit (Dako), and counterstaining was done with hemalaun solution. Antibody titrations and isotype control antibodies were used to determine optimal staining conditions. 


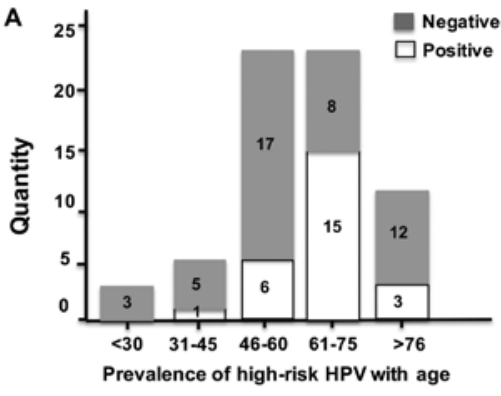

C

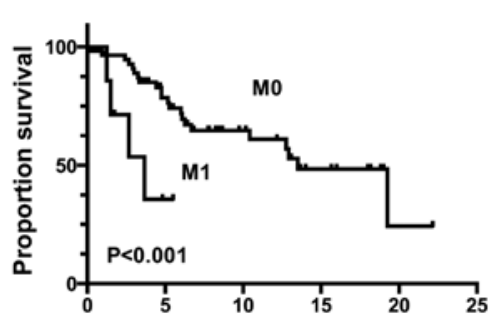

B

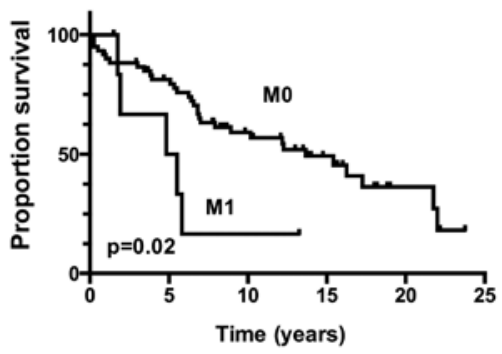

D

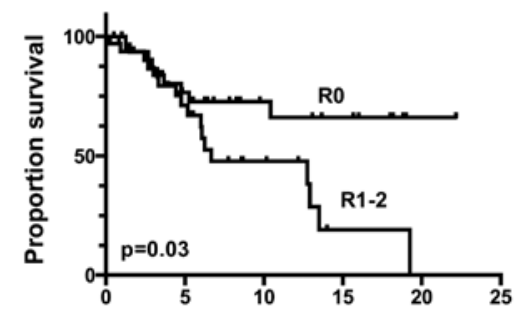

Figure 1. Distribution of HPV status with age (A). Kaplan-Meier analysis indicated that SACC patients with metastases (B) had a poor overall survival, while SACC patients with metastases (C) and positive resection margin (D) had a poor recurrence-free survival.

p16 expression was examined by three independent experienced investigators in a blinded manner, and considered positive if nuclear and cytoplasmic staining was positive.

A semi-quantitative analysis was done, assessing percentage and pattern of staining in the tissue (normal and tumor) using a grading of 0 (negative staining) to 3 (strong staining). The p16 antibody reactivity was scored (32) as follows: negative $(<1 \%$ of the cells were positive), sporadic (isolated cells were positive, but $<5 \%$ ), focal (small cell clusters, but $<25 \%$ of the cells were positive) and diffuse ( $>25 \%$ of the cells were stained). Depending on these criteria, the results were further classified as being negative, weak $(+)$, moderate $(++)$ and strong $(+++)$, respectively.

Statistical analysis. Statistical analysis was performed using SPSS 16.0 software (SPSS, Inc., Chicago, IL, USA). Categorical variables were expressed as percentages and frequencies, and numerical variables were represented as mean \pm SD. Qualitative data were compared using the Chisquare or Fisher's exact test as appropriate. Overall survival (OS) and locoregional recurrence-free survival (LRFS) were determined by using the Kaplan-Meier (KM) method. The Cox multivariate regression model was applied to evaluate hazard ratio (HR) and P-value with the aim to compare the factors with prognostic potential. A P-value of $<0.05$ was regarded as statistically significant.

\section{Results}

Patients. Study participants were between 16 and 90 years of age (median 61.3 years; female to male ratio $2.05: 1$ ) and only patients with no prior history of malignancies were included. Details of the demographic and clinical data for the 67 investigated patients are summarized in Table I. Twenty-three patients (34\%) underwent surgery alone as their sole treatment, $41(62 \%)$ patients underwent surgery and received postoperative radiation, $3(4 \%)$ patients underwent surgery and received postoperative radiochemotherapy. The median follow-up in this population was 102 months (interquartile range, 3-265) among surviving patients. Twenty-six patients (39\%) developed recurrence after initial treatments. Thirty-seven patients $(55 \%)$ had died at the time of last follow-up.

HPV status. HPV-DNA positivity was identified in $28(42 \%)$ of 67 patients in this study cohort of SACC patients (Table II). Subtypes identified were HPV 16, 18, 11, 33, 45, 56 and 59. Frequency was as follows: 17 cases were HPV-16 positive, 4 cases were HPV 18-positive, 3 cases were HPV 11-positive, 2 cases were co-positive for HPV 33 and 59, 1 case was positive for HPV 45, 1 case was co-positive for HPV 45 and 56 (Table II).

No significant associations were observed between HPV-DNA status and clinicopathological parameters (Table I). Ten of $17(59 \%)$ patients were HPV-positive in parotid, 2 of 8 (25\%) patients were HPV-positive in submandibular and 16 of $40(40 \%)$ patients were HPV-positive in the minor salivary glands. There was no significant relation of HPV infections with the tumor sites.

IHC was performed to detect $\mathrm{p} 16^{\mathrm{INK} 4 \mathrm{a}}$ protein and its cellular localization. Overall positivity of p16 ${ }^{\mathrm{INK} 4 \mathrm{a}}$ was $58 \%$. The correlation between positive HPV-DNA status and p16 expression in total specimens was highly significant $(\mathrm{P}<0.001)$ (Table III). A total of $89 \%$ of HPV-DNA-positive primary tumors co-expressed p16 and $64 \%$ of HPV-DNA negative tumors were p16-negative. However, $11 \%$ did not co-express HR-HPV and p16. Positive p16-status has a specificity of $89 \%$ for HPV-DNA positivity in this study. Remarkably, in tumors of three patients low-risk HPV 11 was present as the only type detected.

Expression of Ki-67, p53 and EGFR in SACC. Forty (60\%) of 67 specimens weakly expressed Ki-67, while 27 (40\%) cases showed moderate or strong expression. Higher expression of Ki-67 was correlated with M1 stage $(\mathrm{P}=0.03)$. Thirty-four 


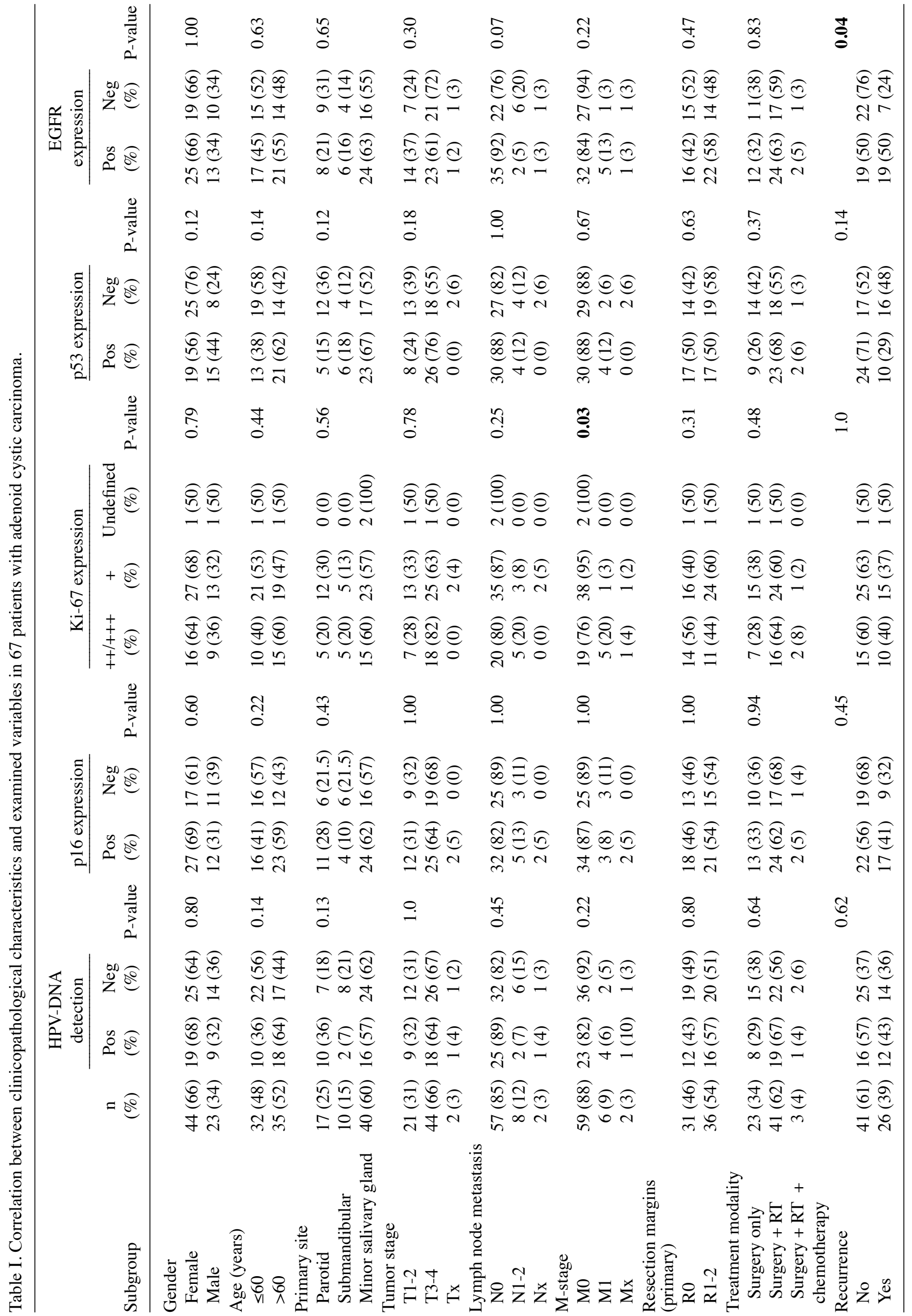


Table II. The presence of human papillomavirus subtypes detected in samples from patients with adenoid cystic carcinoma.

\begin{tabular}{|c|c|c|c|c|c|c|c|c|}
\hline & $\mathrm{n}$ & $\begin{array}{l}\text { HPV-neg } \\
\text { n }(\%)\end{array}$ & $\begin{array}{l}\text { HPV } 16 \\
\mathrm{n}(\%)\end{array}$ & $\begin{array}{c}\text { HPV } 18 \\
\text { n }(\%)\end{array}$ & $\begin{array}{l}\mathrm{HPV} 11^{\mathrm{a}} \\
\mathrm{n}(\%)\end{array}$ & $\begin{array}{c}\text { HPV } 33,59^{b} \\
\text { n }(\%)\end{array}$ & $\begin{array}{c}\mathrm{HPV} 45,56 \\
\mathrm{n}(\%)\end{array}$ & $\begin{array}{c}\text { HPV } 45 \\
\text { n }(\%)\end{array}$ \\
\hline \multicolumn{9}{|l|}{ Primary site } \\
\hline Parotid & 17 & $7(17.9)$ & $6(37.5)$ & $3(75)$ & $0(0)$ & $0(0)$ & $0(0)$ & $1(50)$ \\
\hline Submandibular & 10 & $8(20.5)$ & $1(6.2)$ & $1(25)$ & $0(0)$ & $0(0)$ & $0(0)$ & $0(0)$ \\
\hline Minor salivary gland & 40 & $24(61.5)$ & $9(56.3)$ & $0(0)$ & $3(100)$ & $2(100)$ & $1(100)$ & $1(50)$ \\
\hline
\end{tabular}

${ }^{\mathrm{a} C}$ Classified as low risk-HPV type; ${ }^{\mathrm{b}}$ multiple infections.

Table III. Correlation between HPV-DNA detection with p16, Ki-67, p53 and EGFR expression.

\begin{tabular}{|c|c|c|c|c|}
\hline Variables & $\begin{array}{c}\text { Total } \\
(\mathrm{n}=67) \\
\mathrm{n}(\%)\end{array}$ & $\begin{array}{c}\text { HPV- } \\
\text { positive } \\
(\mathrm{n}=28) \\
\mathrm{n}(\%)\end{array}$ & $\begin{array}{c}\text { HPV- } \\
\text { negative } \\
(\mathrm{n}=39) \\
\mathrm{n}(\%)\end{array}$ & P-value \\
\hline p16 expression & & & & $<0.001$ \\
\hline Negative & $28(42)$ & $3(11)$ & $25(64)$ & \\
\hline Positive & $39(58)$ & $25(89)$ & $14(36)$ & \\
\hline Ki-67 expression & & & & 0.539 \\
\hline 1 & $40(60)$ & $18(64)$ & $22(56)$ & \\
\hline 2 & $17(25)$ & $8(29)$ & $9(23)$ & \\
\hline 3 & $8(12)$ & $2(7)$ & $6(15)$ & \\
\hline Undefined & $2(3)$ & $0(0)$ & $2(5)$ & \\
\hline p53 expression & & & & 0.258 \\
\hline 0 & $33(49)$ & $11(39)$ & $22(56)$ & \\
\hline 1 & $6(9)$ & $2(7)$ & $4(10)$ & \\
\hline 2 & $6(9)$ & $2(7)$ & $4(10)$ & \\
\hline 3 & $22(33)$ & $13(47)$ & $9(24)$ & \\
\hline \multicolumn{5}{|l|}{ EGFR expression } \\
\hline 0 & $29(43)$ & $12(43)$ & $17(44)$ & 0.99 \\
\hline 1 & $13(20)$ & $5(18)$ & $8(21)$ & \\
\hline 2 & $7(10)$ & $3(11)$ & $4(10)$ & \\
\hline 3 & $18(27)$ & $8(29)$ & $10(25)$ & \\
\hline
\end{tabular}

out of 67 (51\%) specimens stained p53-positive. However, p53 expression did not show any correlation with clinicopathological parameters (Table I). Thirty-eight (57\%) of 67 specimens were EGFR positive. EGFR-negative patients with SACC have shown a lower rate of recurrence (Table I).

The correlation of HR-HPV-DNA positivity and Ki-67, p53 and EGFR expression were further analyzed (Table III). No significant relation was found.

Factors affecting survival. Kaplan-Meier survival estimations indicated that SACC patients with M1 stage $(\mathrm{P}=0.02)$ had a reduced OS (Fig. 1). From the Kaplan-Meier analysis of the recurrence-free survival, we found that SACC patients with M1 stage $(\mathrm{P}<0.001)$ and positive resection margins $(\mathrm{P}=0.03)$ had an increased recurrence rate.
Univariate and multivariate analyses of the association of clinical and demographic variables with overall survival of SACC patients are presented in Table IV. Univariate analyses for SACC showed that the status of metastases was significantly associated with poor survival of SACC patients $(\mathrm{P}=0.028)$. Multivariate analyses for SACC showed that the status of metastases $(\mathrm{P}=0.033)$ and $\mathrm{p} 16$ expression $(\mathrm{P}=0.005)$ was an independent prognostic factor.

Univariate analysis showed that both $\mathrm{M} 1$ stage $(\mathrm{P}=0.001)$ and positive resection margins $(\mathrm{R} 1-2)(\mathrm{P}=0.03)$ were significantly associated with a local recurrence risk of SACC patients (Table V). However, multivariate analyses for SACC showed that $\mathrm{M} 1$ stage $(\mathrm{P}=0.002)$, negative HPV status $(\mathrm{P}=0.041)$ and the presence of a positive resection margin $(\mathrm{R} 1-2)(\mathrm{P}=0.012)$ were independent factors for the risk of local recurrence. High grade of Ki-67 expression has shown a trend for occurrence of local recurrence $(\mathrm{P}=0.067)$.

\section{Discussion}

The first objective of the present study was to investigate a potential presence of persisting HPV infections in a larger number of SACC patients as one subgroup of the most frequently occurring carcinomas of the salivary glands. The second aim was to evaluate its potential impact on clinicopathological parameters, disease recurrence and survival. Twenty-eight of 67 SACC patients with HPV positivity were identified demonstrating a more diverse HPV type spectrum than seen in HNSCC. Subtypes 16, 18, 11, 33, 45, 46 and 59 were detected. HPV 16 was the most prevalent subtype seen in 16 patients in accordance to HNSCC. The presence of HPV 11 and 56 were limited to minor salivary glands. Multiple infections of HPV 33 and 59 or 45 and 56 were also found in minor salivary glands. The prevalence of HPV infections was not related to the tumor sites. The subtype variability as well as its relation with tumor sites will be of interest for further investigations in a larger cohort. To date, HPV-related carcinomas of the head and neck tend to be squamous cell carcinomas. There is very sparse information on HPV infection in tumors of the major and minor salivary glands as compared to tumors from other head and neck regions. Hafed et al (33) conducted an analysis of HPV types 16 and 18 in 34 salivary gland neoplasms including 7 SACC. No evidence of HPV infection was found in the 7 SACC specimen. They used, however, in situ hybridization which is prone to lower sensitivity, and subjectivity. Moreover, HR-HPV was not detectable in a study 
Table IV. Univariate and multivariate analysis for factors with potential influence on overall survival in 67 patients with adenoid cystic carcinoma.

\begin{tabular}{|c|c|c|c|c|c|}
\hline & \multicolumn{2}{|c|}{ Univariate } & \multicolumn{3}{|c|}{ Multivariate } \\
\hline & Hazard ratio & P-value & Hazard ratio & $95 \% \mathrm{CI}$ & P-value \\
\hline Tumor stage (pT 3-4 vs. pT 1-2) & 1.122 & 0.477 & 0.8 & $0.377-1.899$ & 0.865 \\
\hline Lymph node metastasis ( $\mathrm{pN} 2-3$ vs. $\mathrm{pN} 0-1$ ) & 1.088 & 0.769 & 1.196 & $0.406-3.520$ & 0.746 \\
\hline Metastases (positive vs. negative) & 2.977 & 0.028 & 3.973 & $1.121-14.083$ & 0.033 \\
\hline HPV (positive vs. negative) & 1.164 & 0.652 & 1.606 & $0.694-3.715$ & 0.268 \\
\hline p16 (positive vs. negative) & 0.657 & 0.207 & 0.286 & $0.119-0.685$ & 0.005 \\
\hline Ki-67 (+ vs. ++/+++) & 1.366 & 0.354 & 1.318 & $0.591-2.937$ & 0.5 \\
\hline p53 (positive vs. negative) & 1.495 & 0.233 & 1.869 & $0.841-4.155$ & 0.125 \\
\hline EGFR (positive vs. negative) & 0.691 & 0.221 & 0.535 & $0.245-1.171$ & 0.118 \\
\hline Resection (R1-2 vs. R0) & 1.345 & 0.378 & 1.928 & $0.828-4.487$ & 0.128 \\
\hline Treatment modality & 1.025 & 0.933 & 0.763 & $0.370-1.574$ & 0.465 \\
\hline \multicolumn{6}{|l|}{ Surgery only } \\
\hline \multicolumn{6}{|l|}{ Surgery + RT } \\
\hline Surgery + RT + chemotherapy & & & & & \\
\hline
\end{tabular}

HPV, human papillomavirus; RT, radiotherapy; EGFR, Epidermal Growth Factor Receptor.

Table V. Univariate and multivariate analysis for factors with potential impact on recurrence-free survival in 67 patients with adenoid cystic carcinoma.

\begin{tabular}{|c|c|c|c|c|c|}
\hline & \multicolumn{2}{|c|}{ Univariate } & \multicolumn{3}{|c|}{ Multivariate } \\
\hline & Hazard ratio & P-value & Hazard ratio & $95 \% \mathrm{CI}$ & P-value \\
\hline Tumor stage (pT 3-4 vs. pT 1-2) & 2.420 & 0.062 & 1.781 & $0.585-5.423$ & 0.310 \\
\hline Lymph node metastasis ( $\mathrm{pN} 2-3$ vs. $\mathrm{pN} 0-1$ ) & 1.848 & 0.221 & 1.912 & $0.537-6.810$ & 0.317 \\
\hline Metastases (positive vs. negative) & 1.351 & 0.001 & 1.468 & $1.154-1.867$ & 0.002 \\
\hline HPV (positive vs. negative) & 1.788 & 0.154 & 3.313 & $1.051-10.445$ & 0.041 \\
\hline p16 (positive vs. negative) & 1.314 & 0.513 & 0.955 & $0.282-3.232$ & 0.941 \\
\hline Ki-67 (+ vs. ++/+++) & 1.321 & 0.497 & 2.628 & $0.935-7.385$ & 0.067 \\
\hline p53 (positive vs. negative) & 0.593 & 0.211 & 0.515 & $0.190-1.394$ & 0.191 \\
\hline EGFR (positive vs. negative) & 0.931 & 0.670 & 1.291 & $0.869-1.916$ & 0.206 \\
\hline Resection (R1-2 vs. R0) & 2.468 & 0.030 & 4.945 & $1.423-17.182$ & 0.010 \\
\hline Treatment modality & 1.046 & 0.903 & 0.617 & $0.187-2.030$ & 0.426 \\
\hline \multicolumn{6}{|l|}{ Surgery only } \\
\hline \multicolumn{6}{|l|}{ Surgery + RT } \\
\hline Surgery + RT + chemotherapy & & & & & \\
\hline
\end{tabular}

HPV, human papillomavirus; RT, radiotherapy; EGFR, Epidermal Growth Factor Receptor.

of primary sinonasal tract and nasopharyngeal adenoid cystic carcinomas (34). Bishop et al (17) found that all specimens were HR-HPV-negative in the 184 salivary gland tumors that arose outside of the sinonasal tract which included 98 ACCs, while 8 HR-HPV-related carcinomas with adenoid cystic-like features were identified that arose in the sinonasal tract. A recent study reported a negative HPV status in a study cohort of salivary gland neoplasms by a sensitive and specific PCR assay (16). To the best of our knowledge, this study is the first to report the evidence of positivity for HPV infection with both high-risk (HPV 16, 18, 33, 45, 56 and 59) and low-risk types (HPV 11) in patients with SACC from using a highly sensitive PCR and a well controlled study material for DNA integrity. p16 positivity has been introduced to be a surrogate marker of HPV infection in cervical and head and neck cancer (35). In the present study, the expression of p16-positive IHC and HPV-DNA positivity was significantly correlated in patients with SACC. However, and in contrast to HNSCC (23), both HPV-DNA positivity and p16 expression did not show any correlation with clinicopathological parameters. As we have 
seen from our previous studies $(35,36)$ and others $(23,37)$ in HNSCC, a certain discrepancy rate of HPV status and p16 expression was observed. In the present study cohort of SACC patients, the subgroup categories of $\mathrm{HPV}^{+} / \mathrm{p}^{+} 6^{+}$patients included $37.3 \%$, of $\mathrm{HPV}^{-} / \mathrm{p} 16^{-} 37.3 \%$, of $\mathrm{HPV}^{-} / \mathrm{p}^{-} 6^{+} 21 \%$ and of $\mathrm{HPV}^{+} / \mathrm{p} 16^{-} 4.4 \%$ patients. In our recent meta-analysis, we found a significantly improved 5-year overall survival for $\mathrm{HPV}^{+} / \mathrm{p}^{+} 6^{+}$ HNSCC, intermediate for the $\mathrm{HPV}^{-} / \mathrm{p}^{1} 6^{+}$subgroup and the shortest survival in $\mathrm{HPV}^{+} / \mathrm{p}^{-} 6^{-}$and $\mathrm{HPV}^{-} / \mathrm{p} 16^{-} \mathrm{HNSCC}(23)$. Therefore, a p16 IHC followed by HPV detection is suggested for subgroup classification referring to prognosis and therapy strategies. In the present study, no significant differences were found when we performed further analysis on these subgroups in relation to clinicopathological parameters and outcome in SACC patients (data not shown). Multivariate analysis has shown that p16 positivity was an independent marker (Table IV) indicating a better survival in patients with SACC, while a presence of HPV-DNA was related to a better recurrence-free survival. This overlap, however, may be due to the limited size of the study cohort.

The two viral oncogenes promoting tumor progression are the HR-HPV derived E6 and E7 genes. E6 protein inactivates p53 thereby inhibiting apoptosis, while E7 protein activates the cell cycle by inhibiting the tumor-suppressor-protein $\mathrm{pRb}$ complex with E2F. This results in liberation of the transcription factor $\mathrm{E} 2 \mathrm{~F}$ and by a positive feedback loop in upregulation of p16 (38). Hence, p16 can be used as a surrogate marker for HPV-related cancer. However, HPV-independent pathways of oncogenesis can also lead to an overexpression of p16. The cellular function of p16 has been recently identified. Knock out of p16 in HPV E7 expressing cells can lead to induction of apoptosis showing a physiological role in transformation despite its original role in the process of senescence (39-42). In another study inactivation of the p16 promotor by methylation has been shown (43). These findings suggested the multiple roles of p16 in carcinogenesis of malignancies in addition to HPV-related pathogenesis, explaining the discrepancy of HPV-DNA and p16 expression $(16,23)$. Further laboratory and clinical studies should be designed with the aim to elucidate the underlying biological cause of the distinct HPV/p16 pattern.

To date, there is no obvious improvement of survival over time which has been reviewed in a large European study on SACC of the head and neck with a 65\% 10-year survival rate (44). In the present study, the overall survival rate of SACC patients was $68 \%$. The potential importance of measurements of certain biomarkers and clinicopathological parameters with impact on disease recurrence and survival are underscored in this study. We found a significantly higher expression of EGFR but not p53 in SACC patients developing recurrence. Despite this finding EGFR expression did not show a significant correlation to survival in SACC patients. In HNSCC, anti-EGFR antibodies such as cetuximab are approved for treatment. However, the addition of cetuximab to radiation or chemo-radiation has resulted in limited benefits to date for the majority of patients with head and neck cancer. Furthermore, EGFR expression levels have not consistently predicted clinical responses to cetuximab. The exact role of EGFR in HNSCC is still debated. As a measure for a high proliferative index, a higher Ki-67 immunoreactivity has been reported to be related to a poor survival in SGC (27).
Our data confirmed its potential prognostic value in the investigated patient cohort with SACC. In addition, there was an association between higher Ki-67 expression and metastases in SACC patients. In HNSCC, HPV-negative tumors appear to be enriched for EGFR and TP53 mutations (25). Herein, there were no correlations of HPV status with p53, EGFR and Ki-67 expression in SACC. Nevertheless, investigations beyond this initial study that incorporate larger numbers of patients with SACC are still necessary to further validate these data.

The standard combination treatment for SACC is radical surgical resection and postoperative radiotherapy. In this study cohort, the treatment modality did not achieve significant impact on survival. Patients with tumor-free resection margins, as expected, had a better recurrence-free survival. SACC will easily infiltrate into adjacent tissues and local recurrences occur despite the above treatment. Therefore, a complete resection with free margin should be achieved wherever possible to reduce the rate of recurrence.

Taken together, our results underscore stratification factors of potential clinical value. Positive resection margins were observed to be related to a disease recurrence despite radiotherapy. The development of distant metastases continues to determine the treatment outcome and predicts a poor survival. In accordance to other studies, higher grade of Ki-67 positivity, representative for a more proliferative tumor, indicates a poorer survival. Most importantly, our results presented for the first time that HPV infection is prevalent in ACCs. Although there were no significant correlations between HPV status and other clinicopathological parameters for survival, the importance of measuring the presence of HPV, and of expression of p53 and EGFR for patient stratification is still of interest to reveal associations of molecularly defined subgroups of SACC. Our findings suggest that p16 positivity could be used as an independent biomarker in predicting prognosis of SACC. Hopefully, the knowledge derived from this study and others will provide new insights into the multiple questions still open in relation to the etiology and carcinogenesis of SACC and treatment strategies.

\section{Acknowledgements}

We are grateful to Berliner Krebsgesellschaft e.V. for financial support. The expert technical assistance by Ursula Schiller and Heidrun Wolter is gratefully acknowledged.

\section{References}

1. Carvalho AL, Nishimoto IN, Califano JA and Kowalski LP: Trends in incidence and prognosis for head and neck cancer in the United States: a site-specific analysis of the SEER database. International journal of cancer. Int J Cancer 114: 806-816, 2005.

2. Bjørndal K, Krogdahl A, Therkildsen MH, Overgaard J, Johansen J, Kristensen CA, Homøe P, Sørensen CH, Andersen E, Bundgaard T, et al: Salivary gland carcinoma in Denmark 19902005: A national study of incidence, site and histology. Results of the Danish Head and Neck Cancer Group (DAHANCA). Oral Oncol 47: 677-682, 2011.

3. Barnes LEJ, Reichart P and Sidransky D: World Health Organization Classification of Tumours. Pathology and Genetics, Head and Neck Tumours. IARC Press, Lyon, 2005.

4. Bell RB, Dierks EJ, Homer L and Potter BE: Management and outcome of patients with malignant salivary gland tumors. J Oral Maxillofac Surg 63: 917-928, 2005. 
5. Buchner A, Merrell PW and Carpenter WM: Relative frequency of intra-oral minor salivary gland tumors: A study of 380 cases from northern California and comparison to reports from other parts of the world. J Oral Pathol Med 36: 207-214, 2007.

6. Terhaard $\mathrm{C} 1$, Lubsen H, Van der Tweel I, Hilgers FJ, Eijkenboom WM, Marres HA, Tjho-Heslinga RE, de Jong JM and Roodenburg JL; Dutch Head and Neck Oncology Cooperative Group. Salivary gland carcinoma: independent prognostic factors for locoregional control, distant metastases, and overall survival: results of the Dutch head and neck oncology cooperative group. Head Neck 26: 681-692; discussion 692-683, 2004.

7. Whatley WS, Thompson JW and Rao B: Salivary gland tumors in survivors of childhood cancer. Otolaryngol Head Neck Surg 134: 385-388, 2006.

8. Zheng R, Wang LE, Bondy ML, Wei Q and Sturgis EM: Gamma radiation sensitivity and risk of malignant and benign salivary gland tumors: A pilot case-control analysis. Cancer 100: 561-567, 2004.

9. Licitra L, Grandi C, Prott FJ, Schornagel JH, Bruzzi P and Molinari R: Major and minor salivary glands tumours. Crit Rev Oncol Hematol 45: 215-225, 2003.

10. Klussmann JP, Müller A, Wagner M, Guntinas-Lichius O, Jungehuelsing M, Sloots T, Ablashi DV and Krueger GR Human herpesvirus type 8 in salivary gland tumors. J Clin Virol 16: 239-246, 2000.

11. Herrero R, Castellsagué X, Pawlita M, Lissowska J, Kee F, Balaram P, Rajkumar T, Sridhar H, Rose B, Pintos J, et al; IARC Multicenter Oral Cancer Study Group: Human papillomavirus and oral cancer: The International Agency for Research on Cancer multicenter study. J Natl Cancer Inst 95: 1772-1783, 2003.

12. Leemans CR, Braakhuis BJ and Brakenhoff RH: The molecular biology of head and neck cancer. Nat Rev Cancer 11: 9-22, 2011.

13. Khan MJ, Castle PE, Lorincz AT, Wacholder S, Sherman M, Scott DR, Rush BB, Glass AG and Schiffman M: The elevated 10 -year risk of cervical precancer and cancer in women with human papillomavirus (HPV) type 16 or 18 and the possible utility of type-specific HPV testing in clinical practice. J Natl Cancer Inst 97: 1072-1079, 2005.

14. Vageli D, Sourvinos G, Ioannou M, Koukoulis GK and Spandidos DA: High-risk human papillomavirus (HPV) in parotid lesions. Int J Biol Markers 22: 239-244, 2007.

15. Lin FC, Chen PL, Tsao TY, Li CR, Jeng KC and Tsai SC: Prevalence of human papillomavirus and Epstein-Barr virus in salivary gland diseases. J Int Med Res 42: 1093-1101, 2014.

16. Senft E, Lemound J, Stucki-Koch A, Gellrich NC, Kreipe H and Hussein $\mathrm{K}$ : Expression of cyclin-dependent kinase inhibitor 2A 16, tumour protein 53 and epidermal growth factor receptor in salivary gland carcinomas is not associated with oncogenic virus infection. Int J Oral Sci 7: 18-22, 2015.

17. Bishop JA, Yonescu R, Batista D, Yemelyanova A, Ha PK and Westra WH: Mucoepidermoid carcinoma does not harbor transcriptionally active high risk human papillomavirus even in the absence of the MAML2 translocation. Head Neck Pathol 8: 298-302, 2014.

18. Isayeva T, Said-Al-Naief N, Ren Z, Li R, Gnepp D and Brandwein-Gensler M: Salivary mucoepidermoid carcinoma: Demonstration of transcriptionally active human papillomavirus 16/18. Head Neck Pathol 7: 135-148, 2013.

19. Isayeva T, Li Y, Maswahu D and Brandwein-Gensler M: Human papillomavirus in non-oropharyngeal head and neck cancers: A systematic literature review. Head Neck Pathol 6 (Suppl 1): S104-S120, 2012.

20. Klussmann JP, Gültekin E, Weissenborn SJ, Wieland U, Dries V, Dienes HP, Eckel HE, Pfister HJ and Fuchs PG: Expression of p16 protein identifies a distinct entity of tonsillar carcinomas associated with human papillomavirus. Am J Pathol 162: 747-753, 2003.

21. Reimers N, Kasper HU, Weissenborn SJ, Stützer H, Preuss SF, Hoffmann TK, Speel EJ, Dienes HP, Pfister HJ, GuntinasLichius O and Klussmann JP: Combined analysis of HPV-DNA, p16 and EGFR expression to predict prognosis in oropharyngeal cancer. International journal of cancer. Int J Cancer 120: 1731-1738, 2007.

22. Fakhry C and Gillison ML: Clinical implications of human papillomavirus in head and neck cancers. J Clin Oncol 24: 2606-2611, 2006.
23. Coordes A, Lenz K, Qian X, Lenarz M, Kaufmann AM and Albers AE: Meta-analysis of survival in patients with HNSCC discriminates risk depending on combined HPV and p16 status. Eur Arch Otorhinolaryngol: Jul 31, 2015 (Epub ahead of print).

24. Sepiashvili L, Bruce JP, Huang SH, O'Sullivan B, Liu FF and Kislinger T: Novel insights into head and neck cancer using next-generation 'omic' technologies. Cancer Res 75: 480-486, 2015.

25. Wichmann G1, Rosolowski M, Krohn K, Kreuz M, Boehm A, Reiche A, Scharrer U, Halama D, Bertolini J, Bauer U, et al: The role of HPV RNA transcription, immune response- related gene expression and disruptive TP53 mutations in diagnostic and prognostic profiling of head and neck cancer. Int $\mathbf{J}$ Cancer 137: 2846-2857 2015

26. Klussmann JP, Mooren JJ, Lehnen M, Claessen SM, Stenner M, Huebbers CU, Weissenborn SJ, Wedemeyer I, Preuss SF, Straetmans JM, et al: Genetic signatures of HPV-related and unrelated oropharyngeal carcinoma and their prognostic implications. Clin Cancer Res 15: 1779-1786, 2009.

27. Luukkaa H, Klemi P, Leivo I, Vahlberg T and Grénman R: Prognostic significance of $\mathrm{Ki}-67$ and p53 as tumor markers in salivary gland malignancies in Finland: An evaluation of 212 cases. Acta Oncol 45: 669-675, 2006.

28. Schmitt M, Bravo IG, Snijders PJ, Gissmann L, Pawlita M and Waterboer T: Bead-based multiplex genotyping of human papillomaviruses. J Clin Microbiol 44: 504-512, 2006.

29. Schmitt M,Dondog B, Waterboer T and Pawlita M: Homogeneous amplification of genital human alpha papillomaviruses by PCR using novel broad-spectrum $\mathrm{GP}^{+}$and $\mathrm{GP}^{+}$primers. J Clin Microbiol 46: 1050-1059, 2008.

30. Muñoz N, Bosch FX, de Sanjosé S, Herrero R, Castellsagué X, Shah KV, Snijders PJ and Meijer CJ; International Agency for Research on Cancer Multicenter Cervical Cancer Study Group: Epidemiologic classification of human papillomavirus types associated with cervical cancer. N Engl J Med 348: 518-527, 2003.

31 Van Dongen JJ, Langerak AW, Brüggemann M, Evans PA, Hummel M, Lavender FL, Delabesse E, Davi F, Schuuring E, García-Sanz R, et al: Design and standardization of PCR primers and protocols for detection of clonal immunoglobulin and T-cell receptor gene recombinations in suspect lymphoproliferations: Report of the BIOMED-2 Concerted Action BMH4-CT98-3936. Leukemia 17: 2257-2317, 2003.

32. Klaes R, Friedrich T, Spitkovsky D, Ridder R, Rudy W, Petry U, Dallenbach-Hellweg G, Schmidt D and von Knebel Doeberitz M: Overexpression of p16(INK4A) as a specific marker for dysplastic and neoplastic epithelial cells of the cervix uteri. Int J Cancer 92: 276-284, 2001.

33. Hafed L, Farag H, Shaker O and El-Rouby D: Is human papilloma virus associated with salivary gland neoplasms? An in situ-hybridization study. Arch Oral Biol 57: 1194-1199, 2012.

34. Thompson LD, Penner C, Ho NJ, Foss RD, Miettinen M, Wieneke JA, Moskaluk CA and Stelow EB: Sinonasal tract and nasopharyngeal adenoid cystic carcinoma: A clinicopathologic and immunophenotypic study of 86 cases. Head Neck Pathol 8: 88-109, 2014

35. Qian X, Wagner S, Ma C, Coordes A, Gekeler J, Klussmann JP, Hummel M, Kaufmann AM and Albers AE: Prognostic significance of ALDH1A1-positive cancer stem cells in patients with locally advanced, metastasized head and neck squamous cell carcinoma. J Cancer Res Clin Oncol 140: 1151-1158, 2014.

36. Qian X, Wagner S, Ma C, Klussmann JP, Hummel M, Kaufmann AM and Albers AE: ALDH1-positive cancer stem-like cells are enriched in nodal metastases of oropharyngeal squamous cell carcinoma independent of HPV status. Oncol Rep 29: 1777-1784, 2013.

37. Robinson M, Sloan P and Shaw R: Refining the diagnosis of oropharyngeal squamous cell carcinoma using human papillomavirus testing. Oral Oncol 46: 492-496, 2010.

38. Hoffmann TK, Arsov C, Schirlau K, Bas M, FriebeHoffmann U, Klussmann JP, Scheckenbach K, Balz V, Bier H and Whiteside TL: T cells specific for HPV16 E7 epitopes in patients with squamous cell carcinoma of the oropharynx. Int J Cancer 118: 1984-1991, 2006.

39. Ressler S, Bartkova J, Niederegger H, Bartek J, ScharffetterKochanek K, Jansen-Dürr P and Wlaschek M: p16INK4A is a robust in vivo biomarker of cellular aging in human skin. Aging Cell 5: 379-389, 2006.

40. McLaughlin-Drubin ME, Park D and Munger K: Tumor suppressor p16INK4A is necessary for survival of cervical carcinoma cell lines. Proc Natl Acad Sci USA 110: 16175-16180, 2013. 
41. Pauck A, Lener B, Hoell M, Kaiser A, Kaufmann AM, Zwerschke W and Jansen-Dürr P: Depletion of the cdk inhibitor p16INK4a differentially affects proliferation of established cervical carcinoma cells. J Virol 88: 5256-5262, 2014.

42. Vékony H, Röser K, Löning T, Raaphorst FM, Leemans CR, Van der Waal I and Bloemena E: Deregulated expression of p16INK4a and p53 pathway members in benign and malignant myoepithelial tumours of the salivary glands. Histopathology 53 658-666, 2008
43. Li J,El-Naggar A and Mao L: Promoter methylation of p16INK4a, RASSF1A, and DAPK is frequent in salivary adenoid cystic carcinoma. Cancer 104: 771-776, 2005.

44. Ciccolallo L, Licitra L, Cantú G, Gatta G and Group EW; EUROCARE Working Group: Survival from salivary glands adenoid cystic carcinoma in European populations. Oral Oncol 45: 669-674, 2009. 